UCRL-ID-140250

\title{
Open Source software licenses for Livermore National Laboratory
}

\author{
L. Busby
}

\section{August 24, 2000}

U.S. Department of Energy

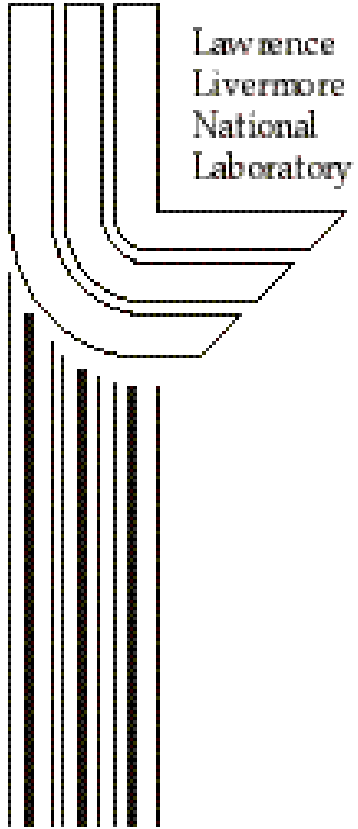

The views represented are those of the author and do not represent those of Lawrence Livermore National Laboratory, the University of California, the United States Government, or any other institution. 


\section{DISCLAIMER}

This document was prepared as an account of work sponsored by an agency of the United States Government. Neither the United States Government nor the University of California nor any of their employees, makes any warranty, express or implied, or assumes any legal liability or responsibility for the accuracy, completeness, or usefulness of any information, apparatus, product, or process disclosed, or represents that its use would not infringe privately owned rights. Reference herein to any specific commercial product, process, or service by trade name, trademark, manufacturer, or otherwise, does not necessarily constitute or imply its endorsement, recommendation, or favoring by the United States Government or the University of California. The views and opinions of authors expressed herein do not necessarily state or reflect those of the United States Government or the University of California, and shall not be used for advertising or product endorsement purposes.

Work performed under the auspices of the U. S. Department of Energy by the University of California Lawrence Livermore National Laboratory under Contract W-7405-Eng-48. 


\title{
Livermore National Laboratory
}

subject: Open Source software licenses
for Livermore National Laboratory

\author{
date: August 1, 2000
}

from: Lee Busby

\begin{abstract}
This paper attempts to develop supporting material in an effort to provide new options for licensing Laboratory-created software. Where employees and the Lab wish to release software codes as so-called Open Source, they need, at a minimum, new licensing language for their released products.
\end{abstract}

Several open source software licenses are reviewed to understand their common elements, and develop recommendations regarding new language.

\section{Introduction}

A personal disclaimer: I am trained as a computer scientist, not a lawyer. Although this paper deals primarily with the language and concepts of law, it is not my purpose to do more than offer a lay opinion about how to address some commonsense needs of many software developers at LLNL. I attempt here to organize a variety of materials in such a way as to facilitate development of new procedures and language as may be required to best support some types of software development at LLNL. This may further what I see as natural interests of the developers, the Lab, the University, and the DOE.

Software development has seen a recent surge of interest in a variety of collaborative methods. These involve new means to bring together participants, new schemes to market the products, new licensing terms to control product dissemination, and a fresh look at many issues surrounding intellectual property. This paper will consider several existing open source licenses, to find their common elements, to identify needs specific to LLNL, and develop preliminary recommendations for changes or additions to current LLNL licensing procedures.

\section{Type of code under consideration}

Software developed at LLNL may be released under a variety of terms. Codes addressed by this paper have typically been released as Unrestricted, defined as follows:

\begin{abstract}
"Code that is not appropriate for filing at ESTSC, is not in development, has no commercial value, or was not designated to be released for a DOE pre-approved program can be released in an unrestricted fashion. The distribution of codes in an unrestricted fashion must follow the review and release procedures." 1
\end{abstract}

\section{Material reviewed}

There is much material written on the subject of open source software licenses at this time, as well as a number of specific license texts. Much of the best material is still due to Richard Stallman, founder of the Free Software Foundation (FSF). ${ }^{2}$ Another good overview may be obtained at the site http://www.opensource.org. This site was founded by the Open Source Initiative.

In preparing this paper, I read license texts from FSF, Mozilla (Netscape), Ricoh, Inc., the University of California BSD distribution, IBM, Inc., MIT, The MITRE Corporation, the Software Carpentry project, the Corporation for National Research Initiatives (Python), Trolltech, Inc., the zlib/libpng project, the Xerox Corporation, Lucent Technologies, and the "Artistic" license, which I

1. http://www-r.llnl.gov/tid/dars/rr-software-options.html

2. See http://www.gnu.org. 
believe is attributed to L. Peter Deutsch, author of Ghostscript. See Appendix B for pointers to most of these texts and related materials.

\section{Elements of an open source license}

The open source licenses I read have a great deal in common, although they differ quite a bit in length and attention to legal details. I abstracted the following set of elements. Some of them seem to be essential in the sense that every license I read has such an element. Others seem to be optional, or they address unusual conditions that can arise in the distribution and use of Open Source software, or they are specific to a particular organization's perceived needs.

\subsection{Origins clause}

This states the names of the original authors and/or owners of the software. It may reserve special rights for the originators. Some licenses explicitly prohibit any misrepresentation about the software's origins in this clause. It may proscribe the form of future additions to the clause in the case where modified versions of the code are released by others.

\subsection{Disclaimer of warranty, liability, etc.}

Software warranty and liability are sometimes treated together, sometimes in separate paragraphs. Although the language varies quite a lot, it always attempts to make a strong and unambiguous statement, "Don't blame us for anything." Some clauses allow warranties to be offered by others, in return for payment.

\subsection{Copyright statement}

Every open source license I read includes a copyright notice. (See Questions, $\S 6$ below.)

\subsection{Distribution rights and obligations}

This is another important clause that appears in some form in every open source license. There is significant variation in this clause because there seem to be several distinct approaches or preferences to open source distribution. Nearly all clauses take pains to explicitly enumerate the rights and responsibilities granted by the license to others.

\subsection{Promulgation of license clause}

This paragraph or sentence states the requirements for transmitting license rights to future users and developers through a chain of modified versions or derived works based upon the given software package. There are two distinct subjects discussed in this clause: One is the literal text of the license notice or referenced exhibits themselves. This is universally required to be passed down in essentially unmodified form. The other subject is the abstract right to read, use, modify, incorporate, sell, or otherwise deal in the software product covered by the license.

\subsection{License version}

Newer or lengthier open source licenses often incorporate a revision number. Many licenses are divided into a generic part, and a specific part that incorporates the generic part by reference. A revision number on the generic part allows it to evolve without the risk of invalidating existing licenses.

\subsection{Definition of terms}

Most licenses find it necessary to define one or more terms, however informally. Some licenses set aside a separate section for definitions.

\subsection{Scope of the license}

Some licenses give explicit statements about what they intend to cover or not cover. This is most important if the license distinguishes between original code and future added or modified code. There may also be parts of a package, such as code documentation, that require different treatment from a licensing standpoint.

\subsection{Severability clause}

This statement attempts to limit damage to the whole license in the case where some part is found to be in conflict with over-riding law. (The remainder of the license still applies.)

\subsection{U.S. Government End Users clause}

This is a boilerplate paragraph that appears in some open source licenses from U.S. corporations. The Mozilla Public License, $\S 10$ is one example. Apparently, it limits license rights transferred to end users who happen to be employees of the U.S. Government to those rights specified in a prior (named) regulation or contract.

\subsection{Termination clause}

This is an explicit statement of the conditions under which recipients of the software package will forfeit the rights transferred by the license. "If you break the rules, you can't play anymore."

\subsection{Adjudication clause}

This paragraph attempts to specify the conditions under which disagreements about the license will 
be dealt with. We wouldn't want to be hauled into court in Norway, would we?

\subsection{Per file exhibit}

Many of the newer open source licenses are quite lengthy. Some of them now specify the text of a short statement that is required to be part of each individual file in the distribution. This exhibit incorporates the entire license by reference, either to a single instance of the complete text that accompanies the distribution, or to a URL (website) where the license may be found.

\section{Deficiencies of the current LLNL Notice}

The current notice attached to most software released as Unrestricted at LLNL is given in Appendix A. The deficiencies I note here have been brought to my attention by a number of software developers at LLNL, as issues that raise questions or cause problems as they have attempted to work with outside users and developers.

- There is no copyright statement. Since this is universally present in open source licenses, its lack causes confusion. See Questions, $§ 6$ below.

- Lines 1-3 of Notice 1 are the origins clause, and 4-5 may be seen as a distribution rights and obligations statement. The Notice does not grant any explicit permission to anyone to do anything whatsoever with the work (software). (It doesn't deny permission either, of course.) A proper statement here needs to give the reader a clear picture of the permissions and rights we intend to transfer.

- Lines 6-16 make up the Disclaimer element. The statement seems to be adequate. Other open source licenses use different language.

- Lines 17-19 define an obligation for certain users or distributors of the software. There are numerous problems with this clause from the point of view of the open source software marketplace:

1. "Commercialization" is not adequately defined. If a web site puts our package into an online index, then accepts revenue from advertisers in proportion to the number of users who click through their page, have they commercialized our package? Does commercialization occur after they start to get revenue? Or when they first decide to build their website?

2. "This product" is not defined. Is it still the same product if one line of code is changed? 1000? Does this make any difference with respect to notification?

3. The mechanics and timing of notification are vague. Is it ok to notify the Lab after commercialization? How long after? Is an email message to, say, the original author of the software package good enough?

The open source marketplace has created a number of new economic niches for the small businessperson. For example, CDROM collections of open source software are a popular, low-cost (and low profit) means of distribution. Compilers of these media will take no risks with a software license. The notification clause in our present Notice is a red flag that may prevent our software from participating in this low margin, but highly visible area of open source distribution.

- The Notice does not contain any Promulgation clause. Future users would appear to be free to remove the Notice at their discretion and redistribute the software under whatever terms they choose.

- The Distribution rights and obligations clause is inadequate. It makes no statement regarding modified versions of the software, or derived works that may incorporate parts of our package. By failing to give clear directions to future users, it confuses the large majority that is happy and eager to use and disseminate our package in good faith. We thereby lose opportunities to broaden our influence and receive credit where it is due.

\section{Questions}

- I am unclear regarding the issue of Copyright. For one thing, Contract 48 appears to limit the ability of the University to assert copyright for computer software to the particular case where commercialization 
would be enhanced. ${ }^{3}$ (More precisely, it seems to require written permission from the DOE on a case-by-case basis.) The software we consider has typically been released as Unrestricted in the past; that category requires us, among other things, to assert the lack of commercial value as a matter of policy. So there appears to be a catch-22 with respect to placing a copyright notice on LLNL-developed open source software at present. A novel interpretation of the phrase about enhancing commercialization might be enough to break this apparent impasse.

Perhaps copyright is superfluous. This element appears in every open source license I have examined, and some writers seem to feel it is quite important. ${ }^{4}$ Others claim that copyright is implicitly presumed (and enforceable), even in the absence of an explicit statement. If we wish to not claim copyright, do we need to explicitly state that our code is "in the public domain", or make some similar statement? Can the remaining elements of our license then continue to be effective, in particular, the clauses about promulgation and inherited distribution rights?

- Contract 48 apparently reserves special rights for the U.S. Government in software produced at LLNL. ${ }^{5}$ A good open source license should allow use of a package in modified form or in derived works. Do the rights of the Government extend to modified or derived works based on our package?

\section{Discussion}

There are (at least) two competing schools of thought regarding open source software at this time. One point of view is embodied in the philosophy of the Free Software Foundation, originators of GNU software and the GNU General Public License (GPL). They believe (and

3. Guide to Disseminating LLNL-Developed Unclassified Software and Legal Issues in Software Development, § 1.1.2.1, UCRL-MA-107389, Revision 2.0, October 1, 1998. Hereinafter referred to as "GDUS2".

4. See, for example, the preamble to the GNU General Public License, at http://www.gnu.org/copyleft/gpl.html.

5. GDUS2, § 1.1.2.3 so write licenses) that access to source code is a fundamental right of the user, and that this right is inherited as software goes through modification and incorporation into myriad separate products. If you as a developer wish to incorporate code licensed under the GPL into your own products, you are obliged to publish your own (source) code under the same (GPL) license. This is the key effect of the so-called copyleft notion.

There is another point of view that, while it may agree in principle with the goal of open access to source code, finds that term of the GPL regarding inherited rights to be unnecessarily coercive toward future developers. Licenses based on this view allow derived or larger works to be created with the new code under a separate, different license. In particular, a secondary developer can incorporate this kind of open source into a proprietary product, and then sell or otherwise market that product without giving away their own source code. I refer to these as permissive open source licenses.

There seems to be good reasoning on both sides, and there seem to be circumstances in the real world where each approach works best. At LLNL, both circumstances could arise. To the extent that we serve the public trust, we should desire to see our work utilized in the Universities and public schools. This might be best served by guaranteeing that some of our software products and works derived from them are available to other researchers in source form. A GPL-like license would be best for this.

To the extent that we maximize our overall impact on the public domain, we should strive to see our products incorporated into the widest set of other works. Some of those will be proprietary, some not. This kind of use is facilitated with a less restrictive license. It is also in keeping with some major University licenses: U.C. Berkeley released its BSD Unix distribution under a fairly permissive license, as did MIT its X-Windows software.

We have a strong ongoing collaboration today with the Center for National Research Initiatives (CNRI), and the Python Consortium, which is responsible for development of the Python computer language. That language is distributed under a permissive open source license, in the sense discussed above. It would be very useful if the (otherwise unrestricted) Python codes we develop at LLNL could be distributed under a 
similar or compatible license. This single collaboration is a great opportunity, both to leverage external development to the advantage of Lab programs, and for us to influence and inform the tools used by many researchers outside LLNL.

Neither of those views of our proper service seems (to me) inconsistent with a third point of view about how to best manage our intellectual property. That point of view would seek to maximize monetary return to the U.S. Government and hence the taxpaying public. In other words, we should be careful not to give away valuable assets. Although my bias toward open source is probably obvious, I do not advocate giving up any part of our current licensing program at LLNL. The decision to seek, and grant, exclusive licenses in return for a fee should continue to be made by software authors working together with IPAC.

A properly managed open source program has benefits that are just as real, albeit more difficult to measure. It will work to increase name recognition for the Laboratory, and prestige and influence for our computer scientists. It will improve job retention and make our jobs more attractive in the first place.

A couple of parting comments about the commercial use notification clause in our current Notice: I would argue against this sort of clause in a future LLNL open source license. I think the statement fails to recognize the actual mechanics of commercialization in the open source arena. If an open source product happens to find commercial success, we will learn about it, regardless of any requirement in our license. We would then have the opportunity to re-release a new version of the given product under a new license, perhaps after negotiation with the third parties involved. This is straight-forward and sensible. I believe the current clause actually reduces the possibility of commercial success by inhibiting the free exchange of our codes.

\section{Recommendations}

I think we need to be able to support either of the major open source license types noted above, based on the preferences of software authors and the judgement of our Office of IPAC. We seem to have some special requirements dictated by our relationship to DOE and the University that would prevent us from using any existing license verbatim, except perhaps in special situations.
I include here a first attempt at a permissive license, similar in spirit to the BSD or MIT licenses, and hope it will be suggestive. I do not attempt to present a more restrictive open source license for LLNL, similar perhaps to the GPL, although I think it is also necessary. Such a license, by precisely enumerating the rights granted, raises hard (for me) questions about the particular rights, if any, that LLNL may wish or be bound to add or subtract. I am not prepared to venture publicly into that deeper subject.

My parenthetical comments about the suggested license text are indented, and in a smaller font.

\subsection{Generic Part}

\section{The LLNL Public License Version 1.0}

This work was produced at the University of California, Lawrence Livermore National Laboratory (UC LLNL) under contract no. W-7405-ENG-48 (Contract 48) between the U.S. Department of Energy (DOE) and The Regents of the University of California (University) for the operation of UC LLNL. The rights of the Federal Government are reserved under Contract 48 subject to the restrictions agreed upon by the DOE and University as allowed under DOE Acquisition Letter 97-1.

\footnotetext{
The above paragraph comes directly from Notice 1 . The "rights of the Federal Government" may need to be explained and limited with respect to modified versions of our work, or derived products based upon it, as discussed earlier.
}

\section{DISCLAIMER}

This work was prepared as an account of work sponsored by an agency of the United States Government. Neither the United States Government nor the University of California nor any of their employees, makes any warranty, express or implied, or assumes any liability or responsibility for the accuracy, completeness, or usefulness of any information, apparatus, product, or process disclosed, or represents that its use would not infringe privately-owned rights. Reference herein to any specific commercial products, process, or service by trade name, trademark, manufacturer or otherwise does not necessarily constitute or imply its 
endorsement, recommendation, or favoring by the United States Government or the University of California. The views and opinions of authors expressed herein do not necessarily state or reflect those of the United States Government or the University of California, and shall not be used for advertising or product endorsement purposes.

The above paragraph was taken directly from Notice 1. The commercial use clause from Notice

1 was deleted.

Permission is hereby granted, free of charge, to any person obtaining a copy of this software and associated documentation files (the "Software"), to deal in the Software without restriction, including without limitation the rights to use, copy, modify, merge, publish, distribute, sublicense, and/or sell copies of the Software, and to permit persons to whom the Software is furnished to do so, subject to the following conditions:

The entire text of this License shall be included in all copies or substantial portions of the Software.

The two paragraphs above come from the MIT license, used by X-Windows, Software carpentry project, and others. "The entire text of this License" originally read "This permission notice". The original text also included a copyright notice, which I moved to the per-file exhibit. See below.

The rights granted are very broad. Note that documentation is also covered, and that permission to modify it without restriction is included. If documents had a separate copyright, e.g., UCRL's, this could be problematic. The Software carpentry project provides a separate optional license for documentation.

THE SOFTWARE IS PROVIDED "AS IS", WITHOUT WARRANTY OF ANY KIND, EXPRESS OR IMPLIED, INCLUDING BUT NOT LIMITED TO THE WARRANTIES OF MERCHANTABILITY, FITNESS FOR A PARTICULAR PURPOSE AND NONINFRINGEMENT. IN NO EVENT SHALL THE AUTHORS OR COPYRIGHT HOLDERS BE LIABLE FOR ANY CLAIM, DAMAGES OR OTHER LIABILITY, WHETHER IN AN ACTION OF CONTRACT, TORT OR OTHERWISE, ARISING FROM, OUT OF OR IN
CONNECTION WITH THE SOFTWARE OR THE USE OR OTHER DEALINGS IN THE SOFTWARE.

\begin{abstract}
The above paragraph also was taken verbatim from the MIT license. It is obviously redundant with parts of the earlier disclaimer, and needs to be combined with that or perhaps removed entirely.
\end{abstract}

\subsection{Per file exhibit}

Copyright (c) 20XX

The Regents of the University of California All rights reserved.

The above clause assumes that my earlier questions
about copyright have been answered.

This program is free software; you can redistribute it and/or modify it under the terms of the LLNL Public License, version 1.0.

\footnotetext{
Some other per-file notices allow "or any later version" as an alternative to referring to a particular version of the generic license.
}

This program is distributed in the hope that it will be useful, but WITHOUT ANY WARRANTY; without even the implied warranty of MERCHANTABILITY or FITNESS FOR A PARTICULAR PURPOSE. See the LLNL Public License for more details.

\footnotetext{
The above and following paragraphs were modeled on text suggested by the FSF, with obvious modifications and extrapolations by this author. A shorter per-file notice would be nice.
}

You should have received a copy of the LLNL Public License along with this program; if not, write to the Office of Industrial Partnerships and Commercialization, Livermore National Laboratory, mailstop L-795, P.O. Box 808, Livermore, CA 94551-0808, or see http://www.llnl.gov/opensource/public_license. 


\section{APPENDIX A}

\section{Notice 1}

"To be used when UC will not exert copyright, but where notification of interest to commercialize is desirable for various reasons."

1 This work was produced at the University of California, Lawrence Livermore National Laboratory

2 (UC LLNL) under contract no. W-7405-ENG-48 (Contract 48) between the U.S. Department of

3 Energy (DOE) and The Regents of the University of California (University) for the operation of UC

4 LLNL. The rights of the Federal Government are reserved under Contract 48 subject to the restrictions 5 agreed upon by the DOE and University as allowed under DOE Acquisition Letter 97-1.

6 DISCLAIMER

7 This work was prepared as an account of work sponsored by an agency of the United States 8 Government. Neither the United States Government nor the University of California nor any of their

9 employees, makes any warranty, express or implied, or assumes any liability or responsibility for the

10 accuracy, completeness, or usefulness of any information, apparatus, product, or process disclosed, or 11 represents that its use would not infringe privately-owned rights. Reference herein to any specific 12 commercial products, process, or service by trade name, trademark, manufacturer or otherwise does 13 not necessarily constitute or imply its endorsement, recommendation, or favoring by the United States 14 Government or the University of California. The views and opinions of authors expressed herein do 15 not necessarily state or reflect those of the United States Government or the University of California, 16 and shall not be used for advertising or product endorsement purposes.

\section{NOTIFICATION OF COMMERCIAL USE}

18 Commercialization of this product is prohibited without notifying the Department of Energy (DOE) or 19 Lawrence Livermore National Laboratory (LLNL). 


\section{APPENDIX B}

\section{Sources for material reviewed}

1. IBM Public License:

http://oss.software.ibm.com/developerworks/opensource/license10.html

2. GNU General Public License: http://www.gnu.org/copyleft/gpl.html

3. GNU Lesser General Public License: http://www.gnu.org/copyleft/lesser.html

4. X11 License: http://www.X.org/terms.htm

5. Mozilla Public License: http://www.mozilla.org/MPL/MPL-1.1.html

6. Xerox ILU License: ftp://ftp.parc.xerox.com/pub/ilu/ilu.html\#copyright

7. Miscellaneous Licenses: http://www.opensource.org/licenses/

8. Software Carpentry Project: http://www.software-carpentry.com

9. GDUS2: http://www-r.llnl.gov/tid/dars/pdf/softwareguide.pdf

10. Center for National Research Initiatives (CNRI): http://www.cnri.reston.va.us. See also http://www.python.org. 